DOI: 10.20472/IAC.2020.054.025

\author{
KETKANOK URWONGSE \\ SUKHOTHAI THAMMATHIRAT OPEN UNIVERSITY, Thailand \\ SASITON BUATHONG \\ SUKHOTHAI THAMMATHIRAT OPEN UNIVERSTY, Thailand
}

\title{
CONDITIONS AND PROBLEMS OF MOBILIZING EDUCATIONAL POLICIES TOWARD PRACTICE OF BASIC EDUCATION SCHOOL ADMINISTRATORS
}

\begin{abstract}
:
The purposes of this research were to study the conditions and problems of mobilizing educational policies toward practice of the school and to study the components of capability for mobilizing educational policies toward practice. Research findings were as follows: (1) regarding the operational conditions of mobilizing educational policies toward practice, it was found that some schools conducted an analysis of the policies while other schools did not do so because they considered that the policies had already been pre-determined for practice; some schools took action to ensure the understanding and acceptance of the policies; most of the schools did not set up any specific working team to be responsible for implementation of the policies, did not evaluate the policies, and did not attempt to create continuity in the implementation; (2) regarding the problems of mobilizing educational policies, it was found that the supervisory work unit issued a lot of policies for the schools to implement without integrating those policies; it also urged the schools to speed up the implementation; on the other hand, the school administrators did not seriously attempt to mobilize the policies, did not analyze the policies, and failed to create the program/project for mobilization of the policies; and (3) the capability for mobilizing educational policies toward practice comprised the following components: the competency for transforming the policy; creating the understanding and acceptance of school personnel; setting up the work structure; resources management; personnel development; monitoring, supervising and evaluation; and creating continuous solidity.
\end{abstract}

\section{Keywords:}

Mobilization, Educational policy, Basic education school, Administrator

JEL Classification: 128, D78 


\section{Introduction}

The mobilization of policies toward practice in order to achieve the goals is the most important part of the policy formulation process because the policy mobilization process is considered to be the linking point between policy formulation and policy evaluation which is the gap that rarely receives the attention (Hargrove, 1975). It is also a cause of the policy or project, that was initially accepted as being appropriate, not achieving success upon implementation. For example, in Thailand even though there have been educational policies or educational laws aiming at educational development throughout the past years, the country's educational quality is still considered to be at the level of seriously needed development. The competitive educational quality of Thailand is still in the unsatisfactory rank. The learners' learning achievement and desirable characteristics are still the continuous problems. These conditions indicate that the formulated educational policies cannot be implemented successfully. Also, results of previous research studies conducted by Thailand Development and Research Institute (TDRI) point out that the goals of educational reform of Thailand are (1) the development of instructional system to fulfill the learner's potential by equipping them with the 21st Century skills; (2) the development of the teacher quality enhancement system; (3) the creation of accountability in the educational system; and (4) the reduction of inequality in various aspects of the educational system. All of these goals are the issues that Thailand must pay serious attention for development by looking toward the future. It is necessary that there must be clear policies for operation and the mobilization of these policies to be implemented in the schools leading to actual practice (The Office of the Education Council, 2016). Therefore, the mobilization of policies toward practice is an important process that needs to be studied and developed.

As for research studies on mobilization of policies toward practice in the past, the majority of studies were the studies on the conditions or characteristics of mobilization of policies toward practice. The majority of research findings showed that the schools implemented the policies for practice. However, there were not many studies on the success or effectiveness of the implementation. For example, Ratanathaworn (2015) studied a model of health promotion policy implementation in basic education schools. She found that some schools implemented the health promotion policy but lacked the clear guidelines for the implementation. As a result, the practice was not in accordance with the policy and the school personnel had little knowledge on the policy. Yawirach (2007) conducted a study to develop a model of implementation of policies toward practice in basic education schools. He also found that the majority of the schools implemented the policies toward practice but lacked the clear and systematic guidelines for the implementation. Also, Tunyaphum (2017) found that the general condition of implementation of policies toward practice in basic education schools was characterized by the lack of clear implementation process. However, Channongwaeng (2002) studied the effectiveness of implementing the 15Year Free-of-Charge Learning Policy toward practice. He found that the effectiveness of implementing the policy was at the rather high level, but there were still problems in many aspects that needed promotion and development such as the promotion for coordination of cooperation with various work agencies, and the enhancement of competencies of the administrators and the organization. Furthermore, from research studies on problems and obstacles of implementation of policies toward practice, it was found that most of them had many problems, such as the lack 
of efficiency in the coordination, the lack of knowledge and ability to transform the policy into practice or to determine appropriate guidelines for practice on the part of the administrators or the policy practitioners (The Office of the Education Council,2001). This is also in agreement with Thongkhao (2013) who states that the leadership factor is a factor that helps determine the success or failure of implementing the policy toward practice. The leader will show his ability in administration, supervising and monitoring of both the personnel and budget, and promoting and facilitating all aspects of the operation in order to support various activities of the policy. Also, the findings from research studies on factors affecting the implementation or mobilization of policies toward practice reveal that the factor of competencies of the organization and the leader is a factor that has influence on the success of implementation of policies toward practice (Chanda,2007; Wilaiphong, 2010; Phaopeng,2010).

Therefore, school administrators need to have competencies in efficiently mobilizing educational policies toward practice, and recently there were the studies and presentation of competency as a whole of school administrators but there is still no study on their competencies for mobilizing educational policies toward practice. Based on the above-mentioned discussion, the researchers are interested in studying the components of competency for mobilizing educational policies toward practice of basic education school administrators. The research findings can be beneficial to school administrators by enabling them to know and be aware of the competencies that they need to develop, and be also beneficial to the supervisory work agency in order to use as the framework for development of competencies for mobilizing educational policies toward practice of the school administrators in the future.

\section{Research Objectives}

2.1 To study the conditions and problems of mobilizing educational policies toward practice of the basic education school administrators.

2.2 To study the components of competency for mobilizing educational policies toward practice of the basic education school administrators.

\section{Research Scope}

This research was conducted specifically with only basic education school administrators under the Office of the Basic Education Commission, Ministry of Education, Thailand by studying the components of their competency for mobilizing policies toward practice which comprise (1) the competency for transforming the policy; (2) the competency for creating the understanding and acceptance of school personnel; (3) the competency for setting up the work structure; (4) the competency for resources management; (5) the competency for personnel development; (6) the competency for monitoring, supervising and evaluation; and (7) the competency for creating continuous solidity. 


\section{$4 \quad$ Research Conceptual Framework}

In determining the conceptual framework of this research, the researchers studied many previous concepts proposed by the academics, namely, (1) the concepts concerning competency and competency development of Shermon (2004), the Office of the Civil Service Commission (2005), and the Office of the Teachers and Educational Personnel Commission (2006); and (2) the concepts concerning mobilization of policy toward practice of Hill and Hupe (2014), Greyerbieht (1993), Mazmanian and Sabatier (1983), Nimphanich (2011), and Yawirach (2007). The formulated conceptual framework of this research is shown in Figure 1 below:

Figure 1: Research Conceptual Framework

\begin{tabular}{|c|c|}
\hline & $\begin{array}{l}\text { Specific competencies for mobilizing } \\
\text { educational policy toward practice } \\
\text { - Policy transformation }\end{array}$ \\
\hline \multirow{7}{*}{$\begin{array}{c}\text { Conditions and problems of } \\
\text { mobilizing educational policy toward } \\
\text { practice }\end{array}$} & $\begin{array}{l}\text { - Creating of understanding and } \\
\text { acceptance }\end{array}$ \\
\hline & - Setting up the work structure \\
\hline & - Resources management \\
\hline & - Personnel development \\
\hline & - Monitoring, supervising and \\
\hline & evaluation \\
\hline & - Creating of continuous solidity \\
\hline
\end{tabular}

\section{$5 \quad$ Expected Outcomes}

5.1 Obtaining the knowledge on the conditions and problems of mobilizing educational policies toward practice of basic education school administrators.

5.2 Obtaining the knowledge on the components of competency for mobilizing educational policies toward practice of the basic education school administrators. The knowledge will enable school administrators to assess themselves and develop their own competencies.

5.3 The supervisory or concerned work agencies can take the components of competency for mobilizing educational policies toward practice of the basic education school administrators to be determined as the criteria for development or screening of school administrators.

\section{$6 \quad$ Research Methodology}

The operational process of this research comprises two steps as follows: 
Step 1 was a study of documents and research studies concerning competencies of school administrators and the mobilization of educational policies toward practice in order to obtain the body of knowledge on the current conditions and problems of mobilizing educational policies toward practice of school administrators and to draft the components of competency for mobilizing educational policies toward practice of basic education school administrators.

Step 2 was the conducting of a focus group discussion on the conditions and problems of mobilizing educational policies toward practice, and the components of competency for mobilizing educational policies toward practice of basic education school administrators. Details of this step were as follows: (1) the key research informants totaling 12 educational personnel consisted of three experts on educational policy and mobilization of educational policy toward practice of the Ministry of Education, two academics on educational administration, two administrators at the educational region level, three school administrators, and two supervisors and teachers; (2) the research instrument was a form containing question guidelines for focus group discussion on the current conditions and problems of mobilizing educational policies toward practice and the drafted components of competency for mobilizing educational policies toward practice; and (3) the focus group discussion data were analyzed with content analysis.

\section{$7 \quad$ Research Results and Discussion}

1) Regarding the conditions of mobilizing educational policies toward practice of the basic education schools, it was found that most educational policies came from the supervisory work unit with the order for the schools to implement them. There were two patterns of implementation by the schools. Large schools with readiness implemented the policies in accordance with the determined steps of implementation, while smaller schools without such readiness did not implement them fully and not in accordance with all steps of implementation. The majority of schools mentioned that they implemented the determined policies but did not do so in accordance with all specified steps clearly. Furthermore, the majority of them did not take action to evaluate the policies and did not implement them on a continuous basis. These findings are probably because the schools perceive that the policies have been handed down from the supervisory work unit with clear guidelines for implementation. Therefore, most school administrators just order the school personnel to implement the policies without the prior analysis of the policies and without the efforts to find out the guidelines for policy implementation that are suitable for the context of the school. These findings are in agreement with the research findings of Ratanathaworn (2015) that the school's policy implementation still lacks clear guidelines for the implementation process; the school personnel have little knowledge and understanding of the policies; the implementation is not in accordance with the assigned plans; and the follow-up and evaluation are incomplete. They are also in agreement with the research findings of Tunyaphum (2017) that the successful implementation of educational policies in school requires that the school administrator must determine the clear principle, process and supporting factors for the implementation. However, the actual conditions of policy implementation in basic education schools in general are still characterized by the adhering to the official rules, regulations and orders without clear transformation of the policies and without consideration for the practice suitable for the context of the school. Results of such implementations are that the teachers lack 
faith and confidence in the policies, do not realize the importance of the policies, lack morale and will power in work performance, and fail to perceive the follow-up and supervision system.

2) Regarding the problems of mobilizing educational policies toward practice of the basic education schools, two types of problems were identified: 1 . The problems caused by external factors of the school which included the following: the supervisory work unit determined many policies without integrating them for the schools to implement; the supervisory work unit pressed for policy implementation, monitoring and follow-up the policies; the directions for understanding of the policies were not clear; and some policies were not responsive to the national policy goals and lacked continuity. It can be seen that most external problems are problems from the supervisory and other work agencies which indicates that the many policies were handed down to the schools from the supervisory and other work units without prior integrating them; several policies are short-term policies and lack continuity; and the supervisory work unit urged the schools to speed up the policy implementation in order to show the performance outcomes as results of those policies. This issue is not in accordance with the guidelines for school-based administration and the decentralization policy which is the main policy of the Ministry of Education. Such actions cause problems for mobilization of policies toward practice which is in agreement with research findings by Gibton, Sabar and Goldring (2000) who conducted a study of opinions of administrators toward the implementation of the decentralization and educational reform policies in Israel and obtained the following research conclusions: the schools were confused and not sure concerning which part of the educational system they were in; and the government policies were contradictory to the decentralization policy, such as ordering the schools to implement the same projects even though the contexts of those schools were different. 2. The problems caused by internal factors of the schools which included the following: the school administrators lacked the determination and sincerity in mobilizing the policies; they did not take action to analyze the policies; the schools failed to create plans/projects for mobilizing the policies and failed to integrate the policies. These findings on internal problems indicate that the majority of problems come from the school administrators and their administration. These findings help to confirm that the competency for mobilizing policies toward practice of the administrator is important for the success of implementing the policies.

3) Regarding the competency for mobilizing educational policies toward practice of the basic education school administrators, it was found that components of the competency comprised those that were in accordance with the steps for mobilizing educational policies toward practice, which were the following: (1) the competency for policy transformation which consisted of the knowledge and understanding of the policy, the ability to analyze the policy, and the ability to determine the steps for policy implementation; (2) the competency for creating the understanding and acceptance of school personnel which consisted of the ability to create good attitudes toward the policy, the ability to create understanding and acceptance, the ability to create points of agreement and create values, the communication skills, the technology usage skills, and the ability to foresee the resistance; (3) the competency for setting up the work structure which consisted of the ability to organize the work structure, and the ability to assign tasks; (4) the competency for resources management which consisted of the ability to procure resources, the ability to procure budgets, and the ability to manage the cooperation from networks and the community; (5) the competency for personnel development which consisted of the ability to 
assess the needs for personnel development, the ability to develop the personnel to equip them with the knowledge of practicing the policies, and the ability to supervise and provision of advices for practicing the policies; (6) the competency for monitoring, supervising and evaluation which consisted of the ability to systematically direct and monitor the work performance, the ability to check and evaluate work performance, and the ability to improve the work performance on a continuous basis; and (7) the competency for creating continuous solidity which consisted of the ability to create the retention of activities, the ability to seek and learn new methods and systems, the ability to create work teams and cooperation, the ability to create networking and coordination, and the ability to manage knowledge. It can be seen that the determined competencies are those derived from the analysis of tasks concerning mobilization of policies toward practice and the opinions of experts on policy development and policy implementation who are experts in the Ministry of Education, academics at the higher education level, and school administrators. These competencies are functional competencies which consist of knowledge, skills and desirable characteristics that the personnel need to possess in order to perform their duty to achieve the determined goals (The Office of the Teachers and Educational Personnel Commission,2006). They are also specific functional competencies (SFC) based on specific task characteristics, i.e. the mobilization of policies toward practice which will show the ability to perform the works based on the function of policy mobilization and show the important basic characteristics of the person, namely, the possession of knowledge and understanding of policies and work performance, the ability to persuade, and the possession of communication and technology skills. These research findings are in agreement with the concepts provided by Boyatziz (1982, cited in Jirasinghe \& Lyons, 1995) who explains that the competencies should comprise the knowledge concerning work and steps of work performance including technical knowledge and inter-personal relationship knowledge; the possession of skills concerning work and behavioral work performance skills such as communication, observation, and listening; the creation of motivation which is the basic requirement for mobilizing the work performance toward success; and the possession of correct attitudes and values concerning work performance.

\section{Conclusion}

The mobilization of policies toward practice is still considered to be an important problem in educational administration in Thailand. The majority of school administrators still perform their roles in mobilizing the policies that is not systematic and based on clear steps of mobilization, and lack the evaluation and creation of continuity in policy mobilization. The above-mentioned problems cause the concerned authority to reconsider and review the competencies for mobilizing the policies. The above-mentioned competencies for mobilizing the policies proposed by the researchers are useful for application as important criteria for consideration of the ability to mobilize educational policies toward practice of basic education administrators. They are also useful for the school administrators in the application for evaluation of their competencies and development for upgrading their competencies which will result on enhancement of the schools' efficiency of mobilizing educational policies toward practice in the future. 


\section{Acknowledgments}

This research received the Academic Research and Development Fund from the Research and Development Institute, Sukhothai Thammathirat Open University.

\section{References}

CHANDA, B. (2007). An analysis of factors affecting the success of educational policy implementation for disadvantaged children in welfare schools under the Office of the Basic Education Commission. (Unpublished Doctoral Dissertation). Burapha University, Chon Buri, Thailand.

CHANNONGWAENG, P. (2002). Effectiveness of fifteen-year free education policy implementation: A case study of schools under jurisdiction of educational service area offices in lower Northeast. (Unpublished Doctoral Dissertation). Ubon Ratchathani University, Ubon Ratchathani, Thailand.

GIBTON, D., SABAR, N. \& GOLDRING, E.B. (2000). How principals of autonomous schools in Israel view implementation of decentralization and restructuring policy: Risks, rights, and wrongs. Educational Evaluation and Policy Analysis, 22(2), pp.193-210.

GREYERBIEHL, D. (1993). Educational policies and practices that support the inclusion of students with disabilities in the general education classroom. West Virginia: Quantity Life Concept.

HARGROVE, E.C. (1975). The missing link: The study of the implementation of social policy. Washington, DC: Urban Institute.

HILL, M. AND HUPE, P. (2014). Implementing public policy: An introduction to the study of operational governance. ( $3^{\text {rd }}$ ed.) London: Sage SAGE Publications.

JIRASINGHE, D. \& LYONS, L. (1995). The competent head: $A$ job analysis of heads' tasks and personality factors. London: Falmer Press.

MAZMANIAN, D. \& SABATIER, P. (1983). Implementation and public policy. Glenview,III.: Scott, Foresman.

NIMPANICH, J. (2011). Policy Implementation, perspectives in political science, politics and public administration, administration and case studies of Thailand. Bangkok: Chulalongkorn University Press.

PHAOPENG, P. (2010). The success of ICT policy implementation in education: Evidence from upper-level secondary schools in Thailand.(Unpublished Doctoral Dissertation).

National Institute of Development Administration, Bangkok, Thailand.

RATANATHAWORN, R. (2015). The policy implementation model of health promotion in Basic Education Institutions. EAU Heritage. Journal of Social Science and Humanity,5(3),281-293.

SHERMON, G. (2004). Competencies based HRM: A strategic resource for competencies mapping. New Delhi: Tata McGraw - Hill.

THE OFFICE OF THE CIVIL SERVICE COMMISSION (OCSC). (2005). Competencies in the Thai civil 
service system. Bangkok: Office of the Civil Service Commission.

THE OFFICE OF THE EDUCATION COUNCIL. (2001). The performance report on driving Education Reform in the Second Decade during 2009-2011. Bangkok: Prickwan Graphic.

THE OFFICE OF THE EDUCATION COUNCIL. (2016). Thai educational competencies in the international arena, 2015. Bangkok: Prickwan Graphic.

THE OFFICE OF THE TEACHER CIVIL SERVICE AND EDUCATIONAL PERSONNEL COMMISSION (OTEPC). (2006). Annual Report 2006. Bangkok: Office of the Teacher Civil Service and Educational Personnel Commission.

THONGKHAO, K. (2013). Unit 3: Implementation of policy and educational plan in the document of policy, planning and educational quality development, Unit 1-5. Nonthaburi: School of Educational studies, Sukhothai Thammathirat Open University.

TUNYAPHUM, K. (2017). A Model for Implementation of the Research for Learning Development Policy toward Practice in Basic Education Schools. Journal of Education,Mahasarakham University, 11(3), 36-47.

WILAIPHONG, S. (2010). Casual model of factors affecting accomplishment of decentralization policy implementation of educational institutions under Songkhla Educational Service Area Office. (Unpublished Master's Thesis). Thaksin university, Songkhla, Thailand.

YAWIRACH, P. (2007). A development of policy implementation model for basic education schools. (Unpublished Doctoral Dissertation). Chulalongkorn University, Bangkok, Thailand. 